\title{
Hyperoxemia in Mechanically Ventilated, Critically Ill Subjects: Incidence and Related Factors
}

\author{
Taiga Itagaki MD, Yuuki Nakano, Nao Okuda MD, Masayo Izawa MD, \\ Mutsuo Onodera MD, Hideaki Imanaka MD PhD, and Masaji Nishimura MD PhD
}

\begin{abstract}
BACKGROUND: Excessive supplemental oxygen causes injurious hyperoxemia. Before establishing the best $\mathrm{P}_{\mathrm{aO}}$ targets for mechanically ventilated patients, it is important to understand the incidence of hyperoxemia and related factors. We investigated oxygenation in mechanically ventilated subjects in our ICU and evaluated factors related to hyperoxemia $\left(\mathrm{P}_{\mathrm{aO}_{2}}>120 \mathrm{~mm} \mathrm{Hg}\right)$ at $48 \mathrm{~h}$ after initiation of mechanical ventilation. METHODS: We retrospectively reviewed the medical records of patients admitted to our ICU from January 2010 to May 2013. Inclusion criteria were $15 \mathrm{y}$ of age or older and administration of mechanical ventilation for $>48 \mathrm{~h}$. Patients at risk of imminent death on admission or who had received noninvasive ventilation were excluded. We collected subject demographics, reasons for mechanical ventilation, and during mechanical ventilation, we collected arterial blood gas data and ventilator settings on the first day of intubation (T1), $48 \mathrm{~h}$ after initiation of mechanical ventilation (T2), and on the day of extubation (T3). Multivariable logistic regression analysis was performed to clarify independent variables related to hyperoxemia at T2. RESULTS: For the study period, data for 328 subjects were analyzed. $\mathbf{P}_{\mathrm{aO}_{2}}$ statistically significantly increased over time to 90 (interquartile range of 74-109) $\mathrm{mm} \mathrm{Hg}$ at $\mathrm{T1}, 105$ (89-120) $\mathrm{mm} \mathrm{Hg}$ at T2, and $103(91-119) \mathrm{mm} \mathrm{Hg}$ at $\mathrm{T} 3(P<.001)$, coincident with decreases in $\mathrm{F}_{\mathrm{IO}_{2}}$ of 0.4 $(0.3-0.5)$ at T1, $0.3(0.3-0.4)$ at $\mathrm{T} 2$, and $0.3(0.3-0.35)$ at $\mathrm{T} 3(P<.001)$. Hyperoxemia occurred in 15.6\% (T1), $25.3 \%$ (T2), and $22.4 \%$ (T3) of subjects. Multivariable logistic regression analysis revealed that hyperoxemia was independently associated with age of $<40$ y (odds ratio $2.6,95 \%$ CI 1.1-6.0), Acute Physiology and Chronic Health Evaluation II scores of $\geq 30$ (odds ratio 0.53, 95\% CI 0.3-1.0), and decompensated heart failure (odds ratio 1.9, 95\% CI 1.1 to 3.5). CONCLUSIONS: During mechanical ventilation of critically ill subjects, $\mathrm{P}_{\mathrm{aO}}$ increased, and $\mathrm{F}_{\mathrm{IO}_{2}}$ decreased. One in 4 subjects were hyperoxemic at T2, and hyperoxemia persisted until T3. Key words: oxygenation; hyperoxemia; mechanical ventilation; oxygen toxicity; acute lung injury; critical care. [Respir Care 2015;60(3):335-340. (C) 2015 Daedalus Enterprises]
\end{abstract}

\section{Introduction}

Administration of oxygen is common and normally beneficial for mechanically ventilated patients. To maintain adequate $\mathrm{P}_{a O_{2}}, \mathrm{~F}_{\mathrm{IO}_{2}}$ is usually set higher than $\mathrm{O}_{2}$ in ambient

\footnotetext{
Drs Itagaki, Okuda, Izawa, Onodera, and Nishimura are affiliated with the Department of Emergency and Critical Care Medicine, University of Tokushima Graduate School, Tokushima, Japan. Mr Nakano is affiliated with the University of Tokushima Medical School, Tokushima, Japan. Dr Imanaka is affiliated with the Department of Emergency and Disaster Medicine, Tokushima University Hospital, Tokushima, Japan.
}

The authors have disclosed no conflicts of interest. air. ${ }^{1}$ Although several studies have provided epidemiological data for $\mathrm{O}_{2}$ administration in critically ill subjects, ${ }^{1-5}$ the evidence is insufficient for deciding the best target values for $\mathrm{P}_{\mathrm{aO}_{2}}$ and optimal titration of $\mathrm{F}_{\mathrm{IO}_{2}}$ during mechanical ventilation.

\footnotetext{
Correspondence: Masaji Nishimura MD PhD, Department of Emergency and Critical Care Medicine, University of Tokushima Graduate School, 3-18-15 Kuramoto-cho, Tokushima 770-8503, Japan. E-mail: nmasaji@ tokushima-u.ac.jp.
}

DOI: $10.4187 /$ respcare. 03451 
Recently, hyperoxemia was identified as an independent in-hospital mortality risk factor for ICU patients. ${ }^{3}$ Adverse outcomes of hyperoxemia were identified in patients after cardiac arrest ${ }^{6}$ and acute myocardial infarction ${ }^{7}$ and in extremely premature infants. ${ }^{8}$ Animal studies have demonstrated that high $\mathrm{F}_{\mathrm{IO}_{2}}$ increases free radicals and causes an influx of inflammatory cells in the lung, ${ }^{9}$ pulmonary permeability, and endothelial cell injury. ${ }^{10,11}$

Despite these concerns, hyperoxemia is accepted by many ICU physicians, who feel no need to adjust ventilator settings as long as $\mathrm{F}_{\mathrm{IO}_{2}}$ is 0.4 or lower. ${ }^{4,12}$ To minimize risk, it is better to know the current levels of oxygenation in mechanically ventilated patients. In this retrospective cohort study, to guide future practice, we set out to determine how $\mathrm{P}_{\mathrm{aO}}$ and $\mathrm{F}_{\mathrm{IO}_{2}}$ change during mechanical ventilation in our ICU and to clarify which factors relate to hyperoxemia.

\section{Methods}

\section{Study Population}

We retrospectively reviewed medical records of patients admitted to our ICU from January 2010 to May 2013. The study protocol was approved by the human ethics committee of Tokushima University Hospital. Because our study was retrospective and because individual subjects were not identified, the requirement for signed informed consent was waived. We included subjects who were older than $15 \mathrm{y}$ and had received mechanical ventilation for $>48 \mathrm{~h}$. Patients at risk of imminent death on ICU admission or treated by noninvasive ventilation were excluded.

\section{Data Collection}

We collected demographic data on age, gender, body mass index, Acute Physiology and Chronic Health Evaluation (APACHE) II scores, reasons for ICU admission and mechanical ventilation, route of admission, and duration of mechanical ventilation. We also reviewed ICU/hospital stay and ICU/hospital mortality. Arterial blood gas analyses of $\mathrm{pH}, \mathrm{P}_{\mathrm{aO}}, \mathrm{P}_{\mathrm{aCO}_{2}}$, and serum lactate levels and ventilator settings of PEEP and $\mathrm{F}_{\mathrm{IO}_{2}}$ data were sampled at 3 time points: within $24 \mathrm{~h}$ after intubation (T1), $\sim 48 \mathrm{~h}$ after initiation of mechanical ventilation (T2), and before extubation (T3). For T1 oxygen values, we used the worst arterial blood gas recorded during the first $24 \mathrm{~h}$. For subjects who subsequently died before extubation, we analyzed only data sampled at T1 and T2. Extubation was defined as the last extubation not followed by re-intubation within $48 \mathrm{~h}$.

\section{QUICK LOOK}

\section{Current knowledge}

Hyperoxemia in mechanically ventilated patients occurs frequently at inspired oxygen concentrations of $<0.50$. The incidence of hyperoxemia appears to be higher in surgical, trauma, and neurosurgical patients. Studies on the consequences of hyperoxemia on pulmonary function and outcomes have provided conflicting results.

\section{What this paper contributes to our knowledge}

In this retrospective study of the incidence of hyperoxemia in mechanically ventilated subjects, despite decreasing $\mathrm{F}_{\mathrm{IO}_{2}}, \mathrm{P}_{\mathrm{aO}_{2}}$ increased with the duration of ventilator support. Hyperoxemia $48 \mathrm{~h}$ after initiation of mechanical ventilation occurred in one quarter of subjects and was associated with age of $<40 \mathrm{y}$, APACHE II score of $\geq 30$, and decompensated heart failure.

\section{Statistical Analysis}

Defining hyperoxemia as $\mathrm{P}_{\mathrm{aO}_{2}}$ of $120 \mathrm{~mm} \mathrm{Hg}$ or higher and assessing single arterial blood gas data at each time point, we carried out analysis of variance of $\mathrm{P}_{\mathrm{aO}_{2}}$ and $\mathrm{F}_{\mathrm{IO}_{2}}$ data obtained during mechanical ventilation, which enabled us to evaluate related variables for hyperoxemia at T2. We compared data for hyperoxemic and non-hyperoxemic subjects using the Mann-Whitney $U$ test for continuous variables and the chi-square test for nominal variables. Subject age, body mass index, APACHE II score, duration of mechanical ventilation, $\mathrm{P}_{\mathrm{aO}_{2}}, \mathrm{pH}, \mathrm{P}_{\mathrm{aCO}}$, serum lactate level, $\mathrm{F}_{\mathrm{IO}_{2}}$, PEEP level, and ICU/hospital stay were analyzed as continuous variables. Nominal variables were age of $<40,40-69$, and $\geq 70 \mathrm{y}$; APACHE II scores of $<15,15-29$, and $\geq 30$; gender; reason for admission; route of admission; reason for mechanical ventilation; and ICU/hospital mortality. To determine independent factors associated with hyperoxemia, we performed multivariable logistic regression analysis, which was carried out using variables that reached a significance threshold of 0.15 in univariate analysis. Statistical calculation was carried out using SPSS 11.0.1 (SPSS, Chicago, Illinois). Data are expressed as median with interquartile range. $P<.05$ was considered statistically significant.

\section{Results}

During the study period, 1,664 patients were admitted to our ICU. Of 340 subjects identified as meeting the inclusion criteria, 328 subjects were included in the final anal- 


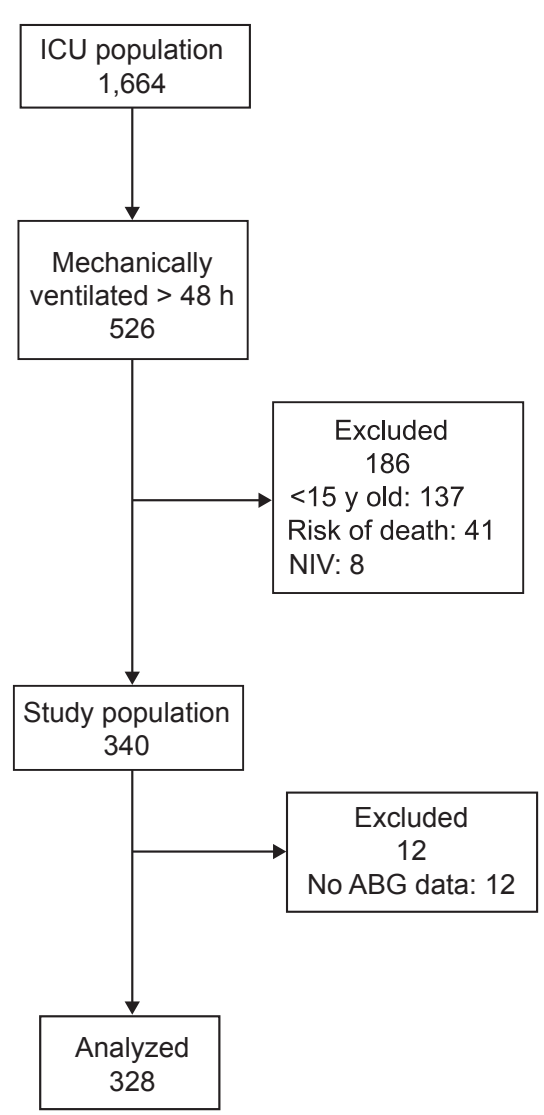

Fig. 1. Flow chart of study participants. NIV = noninvasive ventilation; $A B G=$ arterial blood gas; risk of death = risk of imminent death at ICU admission.

ysis (Fig. 1). Of this study population, 82 subjects $(25 \%)$ died without being extubated. The median age was 68 $(56-75)$ y, 206 subjects were male $(62.8 \%)$, the body mass index was $22(20-25) \mathrm{kg} / \mathrm{m}^{2}$, the APACHE II score was 25 (20-31), and total mechanical ventilation time was 153 (87-294) h. At the 3 time points (T1-T3), $\mathrm{P}_{\mathrm{aO}_{2}}$ was 90 (74-109) $\mathrm{mm} \mathrm{Hg}, 105$ (89-120) $\mathrm{mm} \mathrm{Hg}$, and 103 (91119) $\mathrm{mm} \mathrm{Hg}$, and $\mathrm{F}_{\mathrm{IO}_{2}}$ was $0.4(0.3-0.5), 0.3(0.3-0.4)$, and $0.3(0.3-0.35)$, respectively. The PEEP level was 6 $(6-8) \mathrm{cm} \mathrm{H}_{2} \mathrm{O}$ at all 3 time points. Figure 2 shows changes in $\mathrm{P}_{\mathrm{aO}_{2}}$ and $\mathrm{F}_{\mathrm{IO}_{2}}$ over time during mechanical ventilation. Despite a concurrent decrease in $\mathrm{F}_{\mathrm{IO}_{2}}(P<.001), \mathrm{P}_{\mathrm{aO}_{2}}$ significantly increased over time $(P<.001)$. Subsequently, significant differences were found in $\mathrm{P}_{\mathrm{aO}}$ and $\mathrm{F}_{\mathrm{IO}_{2}}$ between any 2 time points (all $P<.001$ ) except for $\mathrm{P}_{\mathrm{aO}_{2}}$ between T2 and T3 $(P=.93)$. Hyperoxemia occurred in $15.6 \%$ of subjects at $\mathrm{T} 1,25.3 \%$ at $\mathrm{T} 2$, and $22.4 \%$ at $\mathrm{T} 3$.

Table 1 shows the characteristics of hyperoxemic and non-hyperoxemic subjects at T2. Comparable values for each group were (hyperoxemia vs non-hyperoxemia): $\mathrm{P}_{\mathrm{aO}_{2}}$, $133(124-145)$ versus $98(84-108) \mathrm{mm} \mathrm{Hg} ; \mathrm{F}_{\mathrm{IO}_{2}}, 0.3(0.3-$ $0.4)$ versus $0.3(0.3-0.4)$; PEEP, $6(6-8)$ versus $8(6-8)$ $\mathrm{cm} \mathrm{H}_{2} \mathrm{O}$; and duration of mechanical ventilation, 144 (72387) versus $170(105-325) \mathrm{h}$. The most frequent reasons for prolonged mechanical ventilation were altered mental status and airway obstruction. Hyperoxemia at T2 correlated with age of $<40 \mathrm{y}$ ( $P=.03)$, serum lactate level $(P=.03)$, and decompensated heart failure $(P=.04)$. We entered variables including age of $<40 \mathrm{y}$, APACHE II score of $\geq 30$, decompensated heart failure, postoperative care, PEEP, and lactate level into the equation of the proportional odds model. Among them, hyperoxemia was independently associated with age of $<40$ y (odds ratio 2.6, 95\% CI 1.1-6.0) and decompensated heart failure (odds ratio $1.9,95 \%$ CI 1.1-3.5). An APACHE II score of $\geq 30$ was associated with lower incidence of hyperoxemia (odds ratio 0.53 , 95\% CI $0.3-1.0$ ) (Table 2 ).

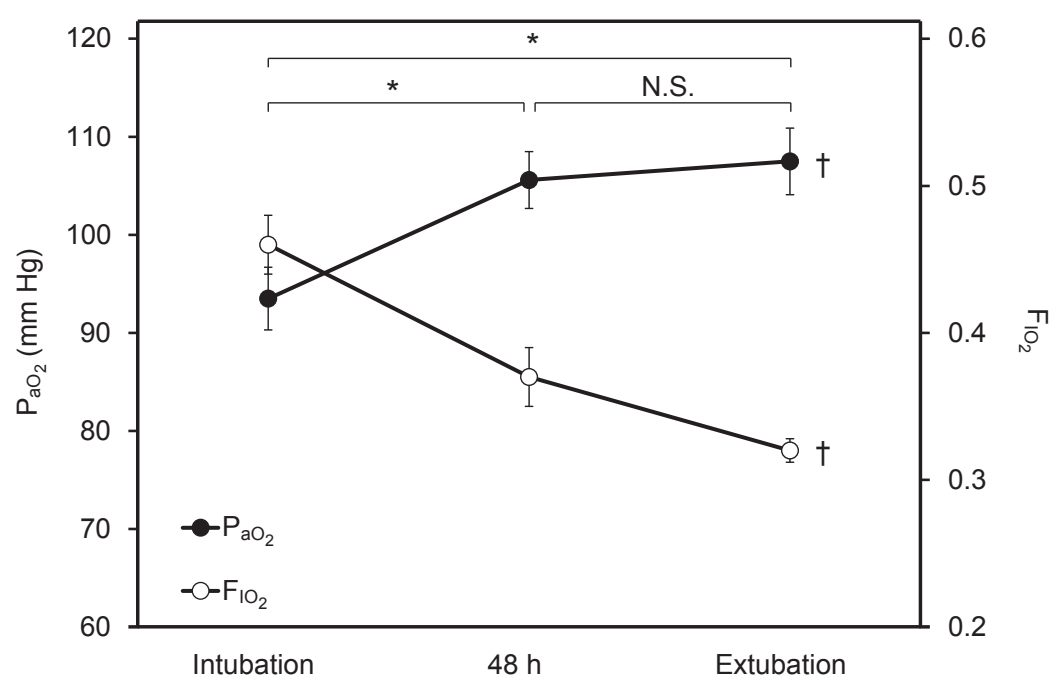

Fig. 2. Change in $\mathrm{P}_{\mathrm{aO}_{2}}$ and $\mathrm{F}_{1 \mathrm{O}_{2}}$ over time during mechanical ventilation. Error bars indicate $95 \%$ confidence intervals. ${ }^{*} P<.001 ; \dagger P<.001$ for trend. NS = not significant. 


\section{Hyperoxemia During Mechanical Ventilation}

Table 1. Comparison of Characteristics of Hyperoxemic and Non-Hyperoxemic Subjects at $48 \mathrm{~h}$ After Initiation of Mechanical Ventilation

\begin{tabular}{|c|c|c|c|}
\hline & $\begin{array}{l}\text { Hyperoxemic Subjects } \\
(n=83)\end{array}$ & $\begin{array}{l}\text { Non-Hyperoxemic Subjects } \\
\qquad(n=245)\end{array}$ & $P$ \\
\hline Age, y & $65(51-73)$ & $69(59-76)$ & .02 \\
\hline$<40 \mathrm{y}, n(\%)$ & $11(13.3)$ & $14(5.7)$ & \\
\hline $40-69$ y, $n(\%)$ & $42(50.6)$ & $114(46.5)$ & \\
\hline$\geq 70 \mathrm{y}, n(\%)$ & $30(36.1)$ & $117(47.8)$ & \\
\hline Males, $n(\%)$ & $47(56.6)$ & $159(64.9)$ & .18 \\
\hline BMI & $22(20-25)$ & $23(19-25)$ & .81 \\
\hline APACHE II score & $23(19-29)$ & $26(20-32)$ & .02 \\
\hline$<15, n(\%)$ & $10(12.0)$ & $16(6.5)$ & \\
\hline $15-29, n(\%)$ & $55(66.3)$ & $148(60.4)$ & \\
\hline$\geq 30, n(\%)$ & $18(21.7)$ & $81(33.1)$ & \\
\hline \multicolumn{4}{|l|}{ Reason for admission, $n(\%)$} \\
\hline Medical, emergency & $56(67.5)$ & $181(73.9)$ & .51 \\
\hline Surgical, emergency & $6(7.2)$ & $16(6.5)$ & \\
\hline Surgical, planned & $21(25.3)$ & $48(19.6)$ & \\
\hline \multicolumn{4}{|l|}{ Route of admission, $n(\%)$} \\
\hline Out-of-hospital & $38(45.8)$ & $95(38.8)$ & .26 \\
\hline In-hospital & $45(54.2)$ & $150(61.2)$ & \\
\hline \multicolumn{4}{|l|}{ Reason for mechanical ventilation, $n(\%)$} \\
\hline Decompensated heart failure & $24(28.9)$ & $45(18.4)$ & .04 \\
\hline Infectious pneumonia & $4(4.8)$ & $19(7.8)$ & .37 \\
\hline Postoperative care & $7(8.4)$ & $37(15.1)$ & .12 \\
\hline Altered mental status & $27(32.5)$ & $62(25.3)$ & .20 \\
\hline Interstitial pneumonia & $0(0.0)$ & $11(4.5)$ & .05 \\
\hline Asthma & $0(0.0)$ & $1(0.4)$ & .56 \\
\hline Airway obstruction & $27(32.5)$ & $62(25.3)$ & .56 \\
\hline Neuromuscular disease & $5(6.0)$ & $13(5.3)$ & .80 \\
\hline Post-cardiopulmonary resuscitation & $4(4.8)$ & $17(6.9)$ & .50 \\
\hline ARDS & $4(4.8)$ & $24(9.8)$ & .16 \\
\hline Pulmonary embolism & $1(1.2)$ & $0(0.0)$ & .09 \\
\hline $\mathrm{F}_{\mathrm{IO}_{2}}$ & $0.3(0.3-0.4)$ & $0.3(0.3-0.4)$ & .65 \\
\hline $\mathrm{P}_{\mathrm{aO}_{2}}, \mathrm{~mm} \mathrm{Hg}$ & $133(124-145)$ & $98(84-108)$ & $<.001$ \\
\hline $\mathrm{P}_{\mathrm{aO}_{2}} / \mathrm{F}_{\mathrm{IO}_{2}}$ & $408(339-447)$ & $280(225-346)$ & $<.001$ \\
\hline PEEP, $\mathrm{cm} \mathrm{H}_{2} \mathrm{O}$ & $6(6-8)$ & $8(6-8)$ & .06 \\
\hline $\mathrm{pH}$ & $7.46(7.43-7.49)$ & $7.45(7.42-7.49)$ & .38 \\
\hline $\mathrm{P}_{\mathrm{aCO}_{2}}, \mathrm{~mm} \mathrm{Hg}$ & $39(35-42)$ & $39(35-43)$ & .34 \\
\hline Lactate, $\mathrm{mmol} / \mathrm{L}$ & $1.2(0.9-1.6)$ & $1.4(1.0-1.9)$ & .03 \\
\hline Duration of mechanical ventilation, $\mathrm{h}$ & $144(72-387)$ & $170(105-325)$ & .16 \\
\hline ICU stay, d & $8(4-13)$ & $8(6-14)$ & .25 \\
\hline ICU mortality, $n(\%)$ & $16(19.3)$ & $66(26.9)$ & .16 \\
\hline Hospital stay, d & $48(26-85)$ & $47(28-79)$ & .81 \\
\hline Hospital mortality, $n(\%)$ & $23(27.7)$ & $91(37.1)$ & .13 \\
\hline \multicolumn{3}{|l|}{ BMI $=$ body mass index } & \\
\hline
\end{tabular}

\section{Discussion}

In this retrospective cohort study, we investigated current oxygen management and factors that contribute to hyperoxemia in mechanically ventilated subjects. $\mathrm{P}_{\mathrm{aO}_{2}}$ significantly increased over time, with $25.3 \%$ of subjects presenting hyperoxemia at $\sim 48 \mathrm{~h}$ after initiation of mechan- ical ventilation. We discovered that age of $<40 \mathrm{y}$, APACHE II score of $\geq 30$, and decompensated heart failure were independently associated with hyperoxemia.

In previous large retrospective studies, ${ }^{1,3}$ when the worst $\mathrm{P}_{\mathrm{aO}_{2}}$ values during the first $24 \mathrm{~h}$ of ICU admission were assessed, the incidence of hyperoxemia varied from $23 \%$ to $50 \%$, with $\mathrm{F}_{\mathrm{IO}_{2}}$ of $0.50-0.62$. In our population, hyper- 
Table 2. Multivariable Logistic Regression Analysis of Hyperoxemia

\begin{tabular}{lcc}
\hline \hline \multicolumn{1}{c}{ Variable } & Odds Ratio (95\% CI) & $P$ \\
\hline Age $<40$ y & $2.58(1.10-6.01)$ & .03 \\
APACHE II score $\geq 30$ & $0.53(0.29-0.97)$ & .04 \\
Decompensated heart failure & $1.94(1.08-3.49)$ & .03 \\
Postoperative care & $0.49(0.19-1.15)$ & .12 \\
PEEP (per $1 \mathrm{~cm} \mathrm{H}_{2} \mathrm{O}$ increase) & $1.04(0.94-1.15)$ & .47 \\
Lactate (per $1.0 \mathrm{mmol} / \mathrm{L}$ increase) & $1.08(0.88-1.44)$ & .55
\end{tabular}

APACHE $=$ Acute Physiology and Chronic Health Evaluation

oxemia was found in $15.6 \%$ of subjects on the first day of mechanical ventilation, less than in previous studies.

Despite setting the $\mathrm{F}_{\mathrm{IO}_{2}}$ at lower levels, $\mathrm{P}_{\mathrm{aO}}$ increased over time, which implies that it may be possible to further decrease $\mathrm{F}_{\mathrm{IO}_{2}}$ during mechanical ventilation. Subsequently, we found no statistically significant differences between $\mathrm{P}_{\mathrm{aO}_{2}}$ at T2 and T3. Suzuki et al ${ }^{2}$ reported that $\mathrm{P}_{\mathrm{aO}_{2}}$ remained unchanged after the second day of mechanical ventilation. For subjects in our study, we examined variables related to hyperoxemia detected at $48 \mathrm{~h}$. On average, they continued to receive mechanical ventilation for another $\sim 6 \mathrm{~d}$ after $\mathrm{T} 2$.

Hyperoxemia is known to be harmful, but how long it can be tolerated and the relationship of $\mathrm{P}_{\mathrm{aO}}$ levels to physical harm have not been clarified. For example, even though 2 large cohort studies ${ }^{1,3}$ assessed the worst $\mathrm{P}_{\mathrm{aO}_{2}}$ during the first $24 \mathrm{~h}$ of ICU admission, it is still not clear whether the risks of hyperoxemia outweigh the advantages of high $\mathrm{P}_{\mathrm{aO}_{2}}$ for patients with pulmonary disease or injury. ${ }^{13}$

Interestingly, we found the highest incidence of hyperoxemia in younger subjects and with low APACHE II scores. The reasons for this are not clear, especially as younger and less sick subjects were considered to have good lung function. Decompensated heart failure was also an independent factor related to hyperoxemia. Pathological decompensated heart failure is caused by transient excessive capillary pressure without increased permeability. ${ }^{14}$ In a multi-center study of noninvasive ventilation in subjects with acute hypoxemic respiratory failure, Antonelli et al ${ }^{15}$ reported decompensated heart failure to be associated with the lowest failure rate of noninvasive ventilation. By improving alveolar diffusing capacity, PEEP works well for decompensated heart failure.

Our study has several limitations. First, this study was performed retrospectively in one center that could sample only $20 \%$ of the entire ICU population during the study period. Moreover, we cannot tell whether possible changes in our practice affected the oxygenation status. Second, we evaluated factors related to hyperoxemia at $48 \mathrm{~h}$ after initiation of mechanical ventilation. We speculated that oxygenation around this time point may represent that for the remaining course because $\mathrm{P}_{\mathrm{aO}}$ at T2 and T3 did not differ significantly (see Fig. 2). However, it is conceivable that the trajectory of care and changes in illness severity may have altered the clinical status of each subject at this time point. Third, the timing and frequency of arterial blood gas analyses differed among the subjects. Although, we monitored both $\mathrm{S}_{\mathrm{pO}_{2}}$ and end-tidal $\mathrm{CO}_{2}$ for all mechanically ventilated subjects, it is difficult to know how much oxygenation fluctuated between arterial blood gas analyses. To solve this problem, the research method using timeweighted averages of variables ${ }^{4}$ may be useful to determine the time patients spent in hyperoxemic ranges. Fourth, even though optimal oxygenation and critical hyperoxemia are still unknown, in line with previous studies, we arbitrarily defined hyperoxemia as $\mathrm{P}_{\mathrm{aO}_{2}}$ of $120 \mathrm{~mm} \mathrm{Hg}$ or higher. Finally, we selected subjects who required mechanical ventilation for $>48 \mathrm{~h}$. These subjects may have been more critically ill and particularly susceptible to changes in oxygen demand and delivery given their illness severity; however, all patients need evaluation.

\section{Conclusions}

In our retrospective cohort study evaluating the incidence of hyperoxemia in mechanically ventilated subjects, despite decreasing $\mathrm{F}_{\mathrm{IO}_{2}}, \mathrm{P}_{\mathrm{aO}}$ significantly increased during mechanical ventilation. We also found that hyperoxemia at $48 \mathrm{~h}$ after initiation of mechanical ventilation was particularly associated with age of $<40 \mathrm{y}$, APACHE II score of $\geq 30$, and decompensated heart failure.

\section{REFERENCES}

1. Eastwood G, Bellomo R, Bailey M, Taori G, Pilcher D, Young P, Beasley R. Arterial oxygen tension and mortality in mechanically ventilated patients. Intensive Care Med 2012;38(1):91-98.

2. Suzuki S, Eastwood GM, Peck L, Glassford NJ, Bellomo R. Current oxygen management in mechanically ventilated patients: a prospective observational cohort study. J Crit Care 2013;28(5):647-654.

3. de Jonge E, Peelen L, Keijzers PJ, Joore H, de Lange D, van der Voort PH, et al. Association between administered oxygen, arterial partial oxygen pressure and mortality in mechanically ventilated intensive care unit patients. Crit Care 2008;12(6):R156.

4. Panwar R, Capellier G, Schmutz N, Davies A, Cooper DJ, Bailey M, et al. Current oxygenation practice in ventilated patients-an observational cohort study. Anaesth Intensive Care 2013;41(4):505-514.

5. Martin DS, Grocott MP. Oxygen therapy in critical illness: precise control of arterial oxygenation and permissive hypoxemia. Crit Care Med 2013;41(2):423-432.

6. Kilgannon JH, Jones AE, Shapiro NI, Angelos MG, Milcarek B, Hunter K, et al. Association between arterial hyperoxia following resuscitation from cardiac arrest and in-hospital mortality. JAMA 2010;303(21):2165-2171.

7. Wijesinghe M, Perrin K, Ranchord A, Simmonds M, Weatherall M, Beasley R. Routine use of oxygen in the treatment of myocardial infarction: systematic review. Heart 2009;95(3):198-202. 


\section{Hyperoxemia During Mechanical Ventilation}

8. Schmidt B, Whyte RK, Asztalos EV, Moddemann D, Poets C, Rabi $\mathrm{Y}$, et al. Effect of targeting higher vs lower arterial oxygen saturations on death or disability in extremely preterm infants: a randomized clinical trial. JAMA 2013;309(20):2111-2120.

9. Zwemer CF, Whitesall SE, D'Alecy LG. Cardiopulmonary-cerebral resuscitation with $100 \%$ oxygen exacerbates neurological dysfunction following nine minutes normothermic cardiac arrest in dogs. Resuscitation 1994;27(2):159-170.

10. Davis WB, Rennard SI, Bitterman PB, Crystal RG. Pulmonary oxygen toxicity. Early reversible changes in human alveolar structures induced by hyperoxia. N Engl J Med 1983;309(15):878-883.

11. Kavanagh BP. Goals and concerns for oxygenation in acute respiratory distress syndrome. Curr Opin Crit Care 1998;4(1):16-20.
12. de Graaff AE, Dongelmans DA, Binnekade JM, de Jonge E. Clinicians' response to hyperoxia in ventilated patients in a Dutch ICU depends on the level of $\mathrm{F}_{\mathrm{IO}_{2}}$. Intensive Care Med 2011;37(1):46-51.

13. Kallet RH, Matthay MA. Hyperoxic acute lung injury. Respir Care 2013;58(1):123-141.

14. Maniatis NA, Kotanidou A, Catravas JD, Orfanos SE. Endothelial pathomechanisms in acute lung injury. Vascul Pharmacol 2008;49(46):119-133.

15. Antonelli M, Conti G, Moro ML, Esquinas A, Gonzalez-Diaz G, Confalonieri M, et al. Predictors of failure of noninvasive positive pressure ventilation in patients with acute hypoxemic respiratory failure: a multi-center study. Intensive Care Med 2001;27(11):17181728.

This article is approved for Continuing Respiratory Care Education credit. For information and to obtain your CRCE

(free to AARC members) visit 